\title{
Exercise-induced hormone and blood fatigue factor responses to branched-chain amino acids administration in the recovery period after exercise: a systematic review and meta-analysis
}

\author{
Azade Sefidari \\ Islamic Azad University Central Tehran Branch \\ Mohammad Hossein Rahimi ( $\square$ mhrahimima@gmail.com) \\ Tehran University of Medical Sciences, Department of Community Nutrition, School of Nutritional Sciences and Dietetics, Tehran, Iran
}

\section{Systematic Review}

Keywords: Branched-chain amino acids, Fatigue, Hormonal responses, Sport, Meta-analysis

Posted Date: October 28th, 2021

DOI: https://doi.org/10.21203/rs.3.rs-1025088/v1

License: (ㅇ) (1) This work is licensed under a Creative Commons Attribution 4.0 International License. Read Full License 


\section{Abstract}

Purpose: Branched-chain amino acid (BCAA) can boost anabolism through an increase in the internal concentration of BCAA, which leads to facilitating anabolic hormone release to stimulate the power of the muscles. Studies on administration of BCAA to minimize fatigue substances during long periods of high intensity exercise have been conducted. However, there are disagreements concerning the results of these studies.

Method: A comprehensive search was performed on electronic databases up to November 2019 for trials evaluating the effects of BCAA on recovery following exercise. Mean \pm standard deviation of follow-up cortisol, insulin, ammonia, and lactate concentrations were extracted to calculate the effect size for meta-analysis.

Results: A total of 146 participants for cortisol and 279 participants for lactate were found from the 7 and 15 studies, respectively. The results revealed a significant effect of BCAA supplementation on cortisol concentration during $120 \leq$ min post exercise follow-up. Moreover, without considering follow-up times, an overall analysis showed that BCAA was effective in reducing blood lactate in aerobic exercise and the trained status of athletes.

Conclusions: The advantages of BCAA administration relate to a reduction in cortisol concentration after $2 \mathrm{~h}$ and ameliorated muscle function because of a probable attenuation of fatigue substances immediately after exercise.

\section{Practical Applications}

The current evidence-based information demonstrates that supplementation with BCAA is better than passive recovery or rest after various forms of damaging and exhausting exercise. The advantages relate to a reduction in cortisol concentration after $2 \mathrm{~h}$ and ameliorated muscle function because of a probable attenuation of fatigue substances immediately after exercise. Furthermore, in aerobic exercise and trained status of participants, the effect of BCAA was significant in achieving lactate reduction.

\section{Introduction}

Exercise is known to release several hormones related to energy production, metabolism, and changes in the concentrations of anabolic and catabolic hormones due to the physiological stress caused by exercise. Following chronic training, the hormonal response to exercise potentiates gains in muscle strength [1]. Hormones are responsible for regulation of muscle protein synthesis through the secretion of anabolic hormones, or muscle protein catabolism with the secretion of catabolic hormones [2]. For example, insulin is an anabolic hormone known to regulate mammalian target of rapamycin (mTOR) and the PI3K-Akt pathway through its activation of upstream enzymes [3] and eventually enhances protein synthesis. Furthermore, cortisol, which stimulates the catabolism of proteins in extrahepatic tissues and increases the concentration of amino acids in plasma, is one of the most effective glucocorticoids secreted from the adrenal glands [4]. Cortisol plasma concentration usually increases during and after exercise, while testosterone may be reduced at the end of exercise and during the hours after exercise [5].

Exercise damages certain muscle fibers that must later undergo a repair process. Hormones, dietary nutrients, and growth factors interact to regulate this restoring of skeletal muscle proteins [6]. A previous study showed that insulin concentrations were significantly higher when subjects consumed a protein-carbohydrate supplement during recovery after a heavy resistance training session $[7,8]$. As a result, dietary energy and nutrients may influence hormonal concentrations independently of exercise and thus help to mediate physiological mechanisms related to recovery from exercise.

Besides, exercise can cause fatigue due to adenosine triphosphate (ATP) depletion and excessive production of fatigue substances such as ammonia and lactate [9]. Finally, the accumulation of fatigue factors can lead to poor performance [10]. Generally, the grade of fatigue depends on internal factors (such as energy storage, muscle mass, and muscle fiber type), while external factors (such as exercise intensity and exercising period) and decline in muscle contraction are closely related to the stimulation of fatigue-triggering metabolites, such as ammonia and lactate [11].

At rest, in response to functional requirements, branched chain amino acids (BCAAs, i.e. leucine, isoleucinem and valine) are used by muscle fibers for protein synthesis and energy production. BCAAs account for $35-40 \%$ of essential amino acids in the diet and are commonly found in sports supplements. BCAAs are reported to reduce fatigue and muscle soreness after exercise and might stimulate muscle protein synthesis to a greater extent than other mixtures of essential amino acids, as well as attenuate exercise-induced protein catabolism $[12,13]$. Furthermore, during intense exercise, BCAA degradation in the muscle is much increased and plasma BCAA 
concentration reduce simultaneously. BCAA supplementation affects the secretion of a number of hormones: for example, leucine can alter concentrations of insulin, growth hormone, and prolactin [14-18].

BCAA might therefore be more important in supporting the immediate recovery period after exercise. However, previous study results have often been contradictory as to the effect of BCAA on blood fatigue factors and hormonal responses after exercise. The purpose of the present systematic review and meta-analysis is, hence, to examine studies that assessed blood fatigue factors and hormonal responses to intake of BCAA supplementation after exercise.

\section{Methods \\ Search strategy}

This systematic review and meta-analysis was conducted according to the guidelines of Preferred Reporting Items for Systematic Reviews and Meta-Analyses (PRISMA) [19]. A computerized literature search was performed, from inception to November 2019, using the Medline and Scopus databases and Cochrane Library, in conjunction with a supplementary Google Scholar search. The following phrases and their combinations were used: "branched chain amino acid", "amino acids, branched-chain", "BCAA", "exercise", "sport supplements", "endocrine response", "cortisol”, "insulin", "fatigue”, "fatigue substance”, "ammonia", and "lactate." Reference lists of all articles were examined for identification of further eligible studies (Fig. 1).

\section{Eligibility criteria}

Studies were selected by applying the following Population-Intervention-Comparator-Outcomes-Study design (PICOS) criteria [19]: (1) healthy subjects received standard oral BCAA supplementation, before and after exercise, as a nutritional strategy; (2) at least one outcome measure of hormones (cortisol and insulin) was reported; (3) at least one outcome measure of fatigue substance (ammonia and lactate) was reported; and (4) original studies that used randomized-controlled trial method. Studies using multiple supplementations, including BCAA in conjunction with another supplement such as carbohydrate [20] and ornithine aspartate (OA) [21], were not considered.

\section{Selection strategy}

After the primary search, titles and abstracts of papers obtained through the search strategy were screened. Two authors ( $\mathrm{MH}$. R and X.W) selected studies according to the inclusion criteria independently. Articles including eligible criteria in the title/abstract screening were selected to be checked in full-text. Parallel clinical trials using a control group or crossover design studies were selected in the systematic review and meta-analysis. All categorized trials were retrieved by either of the authors. On the basis of the information thus collated, we used a standardized form to select the trials eligible for inclusion in the review. Conflicting results were solved by consensus, or the third researcher (L.H).

\section{Data extraction:}

X.W and H.G extracted the following required data: first author's name, publication year and country, research design, age and gender of subjects, sample size, duration of intervention, training status, and BCAA dose. We also extracted mean and standard deviation (SD) of plasma hormones status (cortisol and insulin) and fatigue substance (ammonia and lactate) at baseline and after intervention.

\section{Study quality}

Since it has been accepted that inclusion of trials with a high risk of bias may distort the results of a meta-analysis [19, 22], the Cochrane Collaboration tool for assessing the risk of bias was used. The following factors were assessed: randomization sequence generation; allocation concealment; blinding of participants, personnel, investigator, and assessor; attrition rates; and financial interest of companies (Table 1). These were given a rating of low, unclear, or high risk of bias. An RCT was ranked as having low, medium, or high risk overall based on the key areas of allocation concealment, reporting of attrition rates, and participant and assessor blinding (high = all four factors rated high, medium = two or three factors rated high or unclear, and low = all key areas rated low). 
Cochrane Risk of Bias Assessment

\begin{tabular}{|c|c|c|c|c|c|c|c|c|}
\hline Study & $\begin{array}{l}\text { Random } \\
\text { Sequence } \\
\text { Generation }\end{array}$ & $\begin{array}{l}\text { Allocation } \\
\text { concealment }\end{array}$ & $\begin{array}{l}\text { Blinding of } \\
\text { participants } \\
\text { and personnel }\end{array}$ & $\begin{array}{l}\text { Blinding of } \\
\text { outcome } \\
\text { assessment }\end{array}$ & $\begin{array}{l}\text { Incomplete } \\
\text { outcome } \\
\text { data }\end{array}$ & $\begin{array}{l}\text { Selective } \\
\text { outcome } \\
\text { reporting }\end{array}$ & $\begin{array}{l}\text { Other } \\
\text { sources } \\
\text { of bias }\end{array}$ & $\begin{array}{l}\text { Overall } \\
\text { Risk } \\
\text { of Bias }\end{array}$ \\
\hline $\begin{array}{l}\text { Lysenko } \\
(2016)\end{array}$ & L & L & L & L & L & L & L & Low \\
\hline $\begin{array}{l}\text { Sheikholeslami } \\
\text { (2016) }\end{array}$ & L & L & L & L & L & L & L & Low \\
\hline $\begin{array}{l}\text { Mikulski } \\
\text { (2015) }\end{array}$ & U & $\mathrm{L}$ & $\mathrm{L}$ & L & L & $U$ & $\mathrm{~L}$ & Medium \\
\hline Koo (2014) & L & L & L & L & L & L & L & Low \\
\hline $\begin{array}{l}\text { Atashak } \\
(2014)\end{array}$ & $U$ & L & U & U & L & $U$ & L & Medium \\
\hline Kim (2013) & L & L & L & L & L & L & L & Low \\
\hline Hsu (2011) & U & L & L & L & L & $\mathrm{H}$ & L & Medium \\
\hline $\begin{array}{l}\text { Shimomura } \\
(2010)\end{array}$ & U & L & L & $\mathrm{L}$ & L & $\mathrm{H}$ & L & Medium \\
\hline Apro' (2010) & U & L & L & L & L & $\mathrm{H}$ & L & Medium \\
\hline Sharp (2010) & U & L & U & U & L & $U$ & L & Medium \\
\hline $\begin{array}{l}\text { Matsumoto } \\
(2006)\end{array}$ & U & $\mathrm{L}$ & $\mathrm{L}$ & $\mathrm{L}$ & L & $\mathrm{H}$ & $\mathrm{L}$ & Medium \\
\hline $\begin{array}{l}\text { Karlsson } \\
(2004)\end{array}$ & U & L & L & $\mathrm{L}$ & L & $\mathrm{H}$ & U & Medium \\
\hline $\begin{array}{l}\text { Cheuvront } \\
(2004)\end{array}$ & $U$ & L & L & L & L & $U$ & U & Medium \\
\hline Watson (2004) & L & L & L & L & L & L & L & Low \\
\hline De Palo (1999) & U & L & L & L & L & $\mathrm{H}$ & $U$ & Medium \\
\hline Strüder (1998) & L & L & L & L & L & L & L & Low \\
\hline Mourier (1997) & L & $\mathrm{L}$ & L & L & L & $\mathrm{H}$ & $\mathrm{H}$ & Medium \\
\hline Bigard (1996) & $\mathrm{H}$ & $\mathrm{L}$ & L & U & L & $\mathrm{H}$ & $U$ & High \\
\hline Hall (1995) & $U$ & L & L & L & L & $\mathrm{H}$ & L & Medium \\
\hline McLean (1995) & $U$ & L & U & U & L & $U$ & L & High \\
\hline Carli (1992) & $\mathrm{H}$ & L & U & U & $\mathrm{U}$ & L & $U$ & High \\
\hline
\end{tabular}

\section{Analysis and measures of treatment effect}

For every study, mean differences and standard deviation were computed for continuous variables. Standardized mean differences were used for variables pooled on the different scales. Between-study heterogeneity was assessed using the chi-squared $\left(\mathrm{X}^{2}\right)$ test and quantified using the $\mathrm{I}^{2}$ statistic, which represents the percentage of the total variation across studies that is ascribable to heterogeneity rather than to chance. $I^{2}$ was calculated using the formula: $I^{2}=100 \% \times(Q-d f) / Q$, and an $I^{2}$ value of $75 \%$ or greater was deemed to indicate a high level of inconsistency ( $Q$ is the $\chi 2$ statistic and df is the degrees of freedom). Significant heterogeneity was defined with a P-value of $<0.05$.

Random effect and fixed effect models were applied for assimilating overall effect where evidence of statistical heterogeneity and homogeneity were seen respectively. To determine whether the results could have been affected individually by a single study, an 
influence analysis was carried out [23].

Publication bias was assessed by Begg's rank correlation test and Egger's regression asymmetry test. Statistical analysis was performed using STATA 11.2 software (StataCorp, College Station, Texas, USA).

\section{Results}

\section{Overview of included studies}

We initially identified 354 papers from databases and internet searches and included 22 studies in the present systematic review, with 20 studies selected according to the 4-phase flow diagram described in Fig. 1 in the present meta-analysis. The characteristics of the included studies are summarized in Table 2, which provides an overview of the methodological quality of each selected trial. The included studies were trials with numbers of subjects ranging from 10 to 32, most of which used a crossover design. Participants tended to be young, with a mean age of 24.9. Most of the studies reported acute supplementation (1 day). All participants were men $(n=281)$, except two studies in which only women participated $(n=44)[9,17]$ and two studies in which both men and women participated $(n=34)$ $[24,25]$. 
Table 2

Summary of relevant sources of data included for meta-analysis

\begin{tabular}{|c|c|c|c|c|c|c|c|c|c|c|}
\hline \multirow[t]{2}{*}{ Author } & \multicolumn{5}{|c|}{ Study Design Characteristics } & \multirow{2}{*}{$\begin{array}{l}\text { average } \\
\text { age }(Y)\end{array}$} & \multicolumn{2}{|c|}{ Sample Size } & \multirow{2}{*}{$\begin{array}{l}\text { Hormone } \\
\text { Status }\end{array}$} & \multirow{2}{*}{$\begin{array}{l}\text { Fatigue } \\
\text { substance } \\
\text { Status }\end{array}$} \\
\hline & design & $\begin{array}{l}\text { training } \\
\text { status }\end{array}$ & $\begin{array}{l}\text { BCAA dose } \\
\text { (gr) }\end{array}$ & $\begin{array}{l}\text { Duration } \\
\text { (D) }\end{array}$ & gender & & BCAA & Control & & \\
\hline $\begin{array}{l}\text { Lysenko } \\
\text { (2016) }\end{array}$ & $\mathrm{C}-\mathrm{O}$ & $\mathrm{t}$ & 7 & 1 & M & $18-30$ & 9 & 9 & $\begin{array}{l}\text { 三 } \\
\text { Cortisol, } \\
\equiv \text { Insulin }\end{array}$ & $\equiv$ Lactate \\
\hline $\begin{array}{l}\text { Sheikholeslami } \\
\text { (2016) }\end{array}$ & $\mathrm{C}-\mathrm{O}$ & u & 4.5 & 1 & $\mathrm{~F}$ & 22 & 10 & 10 & $\begin{array}{l}\text { 三 } \\
\text { Cortisol, } \\
\equiv \text { Insulin }\end{array}$ & \\
\hline $\begin{array}{l}\text { Mikulski } \\
\text { (2015) * }\end{array}$ & $\mathrm{CO}$ & $\mathrm{t}$ & $16(+O A)$ & 1 & M & 32.6 & 11 & 11 & & $\stackrel{\uparrow}{\text { Ammmonia }}$ \\
\hline Koo (2014) & $\mathrm{CO}$ & $\mathrm{t}$ & 3.15 & 6 & M & 17.2 & 5 & 5 & & $\begin{array}{l}\equiv \\
\text { Ammonia, } \\
\equiv \text { Lactate }\end{array}$ \\
\hline $\begin{array}{l}\text { Atashak } \\
(2014)\end{array}$ & $\mathrm{RCT}$ & u & 1.5 & 1 & M & 21.5 & 10 & 10 & $\begin{array}{l}\text { 三 } \\
\uparrow \text { Insulisol, } \\
\text { In }\end{array}$ & \\
\hline $\operatorname{Kim}(2013)$ & $\mathrm{RCT}$ & u & 5.5 & 1 & M & 23 & 13 & 13 & & $\begin{array}{l}\uparrow \\
\text { Ammonia, } \\
\downarrow \text { Lactate }\end{array}$ \\
\hline Hsu (2011) & $\mathrm{C}-\mathrm{O}$ & $\mathrm{t}$ & 2 & 1 & $M$ & 23.4 & 14 & 14 & $\uparrow$ Insulin & $\begin{array}{l}\equiv \\
\text { Ammonia, } \\
\equiv \text { Lactate }\end{array}$ \\
\hline $\begin{array}{l}\text { Shimomura } \\
\text { (2010) }\end{array}$ & $\mathrm{C}-\mathrm{O}$ & u & 5.5 & 1 & $\mathrm{~F}$ & 22.2 & 12 & 12 & $\equiv$ Insulin & $\begin{array}{l}\uparrow \\
\text { Ammonia, } \\
\equiv \text { Lactate }\end{array}$ \\
\hline Sharp (2010) & $\mathrm{C}-\mathrm{O}$ & $\mathrm{t}$ & 3.3 & 28 & $M$ & 22.9 & 8 & 8 & $\stackrel{\downarrow}{\text { Cortisol }}$ & \\
\hline Apro' (2010) & $\mathrm{C}-\mathrm{O}$ & u & 6.2 & 1 & $M \& F$ & 26 & 9 & 9 & $\equiv$ Insulin & $\equiv$ Lactate \\
\hline $\begin{array}{l}\text { Matsumoto } \\
(2006)\end{array}$ & $\mathrm{C}-\mathrm{O}$ & u & 2 & 1 & $M \& F$ & 26 & 8 & 8 & $\equiv$ Insulin & $\equiv$ Lactate \\
\hline $\begin{array}{l}\text { Karlsson } \\
(2004)\end{array}$ & $\mathrm{C}-\mathrm{O}$ & u & 7.3 & 1 & $M$ & 25 & 6 & 6 & $\equiv$ Insulin & \\
\hline $\begin{array}{l}\text { Cheuvront } \\
(2004)\end{array}$ & $\mathrm{C}-\mathrm{O}$ & $\mathrm{t}$ & 10 & 1 & $M$ & 21 & 7 & 7 & & $\equiv$ Lactate \\
\hline Watson (2004) & $\mathrm{CO}$ & $\mathrm{t}$ & 6 & 1 & $M$ & 28.5 & 8 & 8 & & $\begin{array}{l}\uparrow \\
\text { Ammonia, } \\
\equiv \text { Lactate }\end{array}$ \\
\hline De Palo (1999) & $\mathrm{RCT}$ & $\mathrm{t}$ & 9.64 & 30 & $M$ & 32.8 & 6 & 5 & & $\downarrow$ Lactate \\
\hline Davis(1998) * & $\mathrm{C}-\mathrm{O}$ & $\mathrm{t}$ & $\begin{array}{l}7+ \\
\text { carbohydrate }\end{array}$ & 1 & $M \& F$ & $\wedge$ & 16 & 16 & $\equiv$ Insulin & $\equiv$ Lactate \\
\hline Strüder (1998) & $\mathrm{C}-\mathrm{O}$ & $\mathrm{t}$ & 7 & 1 & $M$ & 25.5 & 10 & 10 & $\begin{array}{l}\equiv \\
\text { Cortisol, } \\
\equiv \text { Insulin }\end{array}$ & $\begin{array}{l}\equiv \\
\text { Ammonia, } \\
\equiv \text { Lactate }\end{array}$ \\
\hline Mourier (1997) & $\mathrm{C}-\mathrm{O}$ & $\mathrm{t}$ & 64 & 19 & $M$ & 23 & 6 & 6 & $\equiv$ Insulin & $\equiv$ Lactate \\
\hline \multicolumn{11}{|c|}{$\begin{array}{l}\mathrm{C}=\text { Cortisol; } \mathrm{I}=\text { Insulin; } \mathrm{BCAA}=\text { branched-chain amino acid; } \mathrm{OA}=\text { ornithine aspartate; } \mathrm{RCT}=\text { randomized controlled trial; } \mathrm{C}-\mathrm{O}=\text { cross- } \\
\text { over studies; } \mathrm{M}=\text { men; } \mathrm{F}=\text { Female; } \mathrm{D}=\text { days; } \mathrm{Y=years;} \mathrm{T}=\text { trained; } \mathrm{U}=\text { untrained }\end{array}$} \\
\hline \multicolumn{11}{|c|}{ ^Excluded from meta-analysis; ^Unspecified or unknown. } \\
\hline $\begin{array}{l}\uparrow \text { BCAA group } \mathrm{BCA} \\
\text { significant diffe }\end{array}$ & Icant & gher cor & are to contr & $\mathrm{dp} ; \downarrow$ BC & group & ficant & wer & are to & broup & No \\
\hline
\end{tabular}




\begin{tabular}{|c|c|c|c|c|c|c|c|c|c|c|}
\hline \multirow[t]{2}{*}{ Author } & \multicolumn{5}{|c|}{ Study Design Characteristics } & \multirow{2}{*}{$\begin{array}{l}\text { average } \\
\text { age }(Y)\end{array}$} & \multicolumn{2}{|c|}{ Sample Size } & \multirow{2}{*}{$\begin{array}{l}\text { Hormone } \\
\text { Status }\end{array}$} & \multirow{2}{*}{$\begin{array}{l}\text { Fatigue } \\
\text { substance } \\
\text { Status }\end{array}$} \\
\hline & design & $\begin{array}{l}\text { training } \\
\text { status }\end{array}$ & $\begin{array}{l}\text { BCAA dose } \\
(\mathrm{gr})\end{array}$ & $\begin{array}{l}\text { Duration } \\
\text { (D) }\end{array}$ & gender & & BCAA & Control & & \\
\hline Bigard (1996) & $\mathrm{RCT}$ & $\mathrm{t}$ & 7.8 & 30 & M & $25-42$ & 12 & 12 & $\begin{array}{l}\equiv \\
\text { Cortisol, } \\
\uparrow \text { Insulin }\end{array}$ & $\begin{array}{l}\equiv \\
\text { Ammonia, } \\
\equiv \text { Lactate }\end{array}$ \\
\hline Hall (1995) & $\mathrm{CO}$ & $\mathrm{t}$ & 7.8 & 1 & M & 23.3 & 10 & 10 & & $\stackrel{\uparrow}{\uparrow}$ Ammonia \\
\hline Hall (1995) & $\mathrm{CO}$ & $\mathrm{t}$ & 23.4 & 1 & M & 23.3 & 10 & 10 & & $\stackrel{\uparrow}{\uparrow}$ Ammonia \\
\hline McLean (1995) & $\mathrm{CO}$ & $\wedge$ & 5.5 & 1 & M & 24.4 & 5 & 5 & & $\begin{array}{l}\uparrow \\
\text { Ammonia, } \\
\downarrow \text { Lactate }\end{array}$ \\
\hline Carli (1992) & $\mathrm{C}-\mathrm{O}$ & $\mathrm{t}$ & 10 & 1 & M & 35.5 & 14 & 14 & $\begin{array}{l}\text { 三 } \\
\uparrow \text { Intisol, } \\
\uparrow \text { Insulin }\end{array}$ & \\
\hline \multicolumn{11}{|c|}{$\begin{array}{l}\mathrm{C}=\text { Cortisol; } \mathrm{I}=\text { Insulin; } \mathrm{BCAA}=\text { branched-chain amino acid; } \mathrm{OA}=\text { ornithine aspartate; } \mathrm{RCT}=\text { randomized controlled trial; } \mathrm{C}-\mathrm{O}=\text { cross- } \\
\text { over studies; } \mathrm{M}=\text { = men; } \mathrm{F}=\text { = Female; } \mathrm{D}=\text { days; } \mathrm{Y}=\text { =ears; } \mathrm{T}=\text { =trained; } \mathrm{U}=\text { untrained }\end{array}$} \\
\hline \multicolumn{11}{|c|}{ *Excluded from meta-analysis; ^Unspecified or unknown. } \\
\hline $\begin{array}{l}\uparrow \text { BCAA group si } \\
\text { significant differ }\end{array}$ & $\begin{array}{l}\text { nificantly } \\
\text { nce betw }\end{array}$ & $\begin{array}{l}\text { gher com } \\
\text { n trials }\end{array}$ & pare to contrc & up; $\downarrow$ BCA & group s & ificantly & wer co & bare to $\mathrm{c}$ & trol group; & \\
\hline
\end{tabular}

The total participant pool for insulin was 240 , comprising 110 untrained and 130 trained participants. In the seven publications included in the study for cortisol, the total participant pool was 146, comprising 40 untrained and 106 trained participants. Moreover, the total participant pool for ammonia and lactate as fatigue substance factors was 178 and 279 , respectively. This numbers are inclusive of individuals who were dropouts in some studies.

All studies reported multiple follow-up observations for each outcome. Although most studies reported follow-ups at multiple minutes and hours (e.g., post-exercise for both intervention and placebo at 10, 20, 30, 40, and $50 \mathrm{~min}$, and 1, 2, and $3 \mathrm{~h}$ after the start of exercise and supplementation). This review focused on outcomes undertaken immediately post exercise and the subsequent minutes and hours after the completion of the recovery intervention.

\section{Findings of the systematic review}

Among the studies, some of them did not meet the criteria for inclusion in the meta-analysis. These were therefore explained as a systematic review. Due to the heterogeneity of the study outcomes, designs, and interventions, a meta-analysis was not undertaken for insulin and ammonia concentration. The number of studies demonstrating a significant effect of BCAA on insulin and cortisol was lower compared to the number of studies which showed no effect. It should be noted that a significant effect hormones was clearly reported by the lower-quality studies [26-30], whereas high-quality studies noted no significant effect on hormones. Among the seven publications that studied the effect of BCAA on cortisol, only Sharp et al. [26] reported a significant effect on cortisol reduction.

Atashak et al. [27] suggested that ingestion of $1.5 \mathrm{~g} /$ day BCAA played a role in increasing insulin concentration after resistance exercises in comparison with placebo in the 1 and 2 hours after exercise. These results are consistent with two studies with ingestion of $2 \mathrm{~g} /$ day BCAA [28], which increased insulin 40 and $60 \mathrm{~min}$ after exercises and $10 \mathrm{~g} /$ day BCAA [30], which, in turn, increased insulin concentration $90 \mathrm{~min}$ after exercise, in comparison with placebo. Furthermore, Bigard et al. studied doses of $10 \mathrm{~g} /$ day BCAA supplementation for a month and observed a significant increase of insulin concentration immediately after exercise, compared to placebo [29]. However, most of the studies did not report any positive effect of BCAA supplementation on insulin concentration.

In addition, the number of studies demonstrating a significant effect on ammonia and lactate was equivalent to the number of studies which showed no effect. Also, a long duration of supplementation over several days before damaging exercise (at least 6 days prior to damaging exercise in three of the studies $[10,29,31])$ showed no effect of BCAA supplementation on fatigue substances. Mikulski et al. (31) suggested that ingestion of combined BCAA and ornithine aspartate played a role in increasing ammonia 90 min after exercise, in comparison with placebo. Although Hall et al. demonstrated the effect of a low and a high dose of BCAA ( 7.8 and $23.4 \mathrm{~g} / \mathrm{day}$ ) on 
increasing ammonia exactly after exercise [32]. Three studies $[9,33,34]$ used $5.5 \mathrm{~g} /$ day BCAA and showed a positive role of BCAA in increasing ammonia and decreasing lactate after exercise, with the exception of Shimomura et al. who did not see this effect on lactate [9], an observation consistent with that of Watson et al. [35], who used $6 \mathrm{~g} /$ day BCAA.

\section{Findings of the meta-analysis}

\section{Analysis}

We found the source of the heterogeneity for cortisol and lactate which was follow-up times that a subgroup analyses was conducted for follow-up time ( $<60, \geq 60$ and $\geq 120$ minutes). In addition, one study [26] with supplementation over 1 day excluded for cortisol concentration; therefore we meta-analyzed exercise-induced cortisol responses to acute BCAA administration (less than 1 day administration).

\section{The effects of BCAA supplementation on cortisol concentration}

The pooled results from five studies with 106 participants that examined the impact of BCAA supplementation on cortisol concentration are presented in Fig. 2. Data include weighted mean difference (WMD) and 95\% confidence interval (CI). It is important to consider the overall relevance of these findings, especially as to the significant reduction in cortisol. The positive effects of BCAA could cause reductions in cortisol concentration regardless of follow-up times (overall WMD $=-0.86 \mu \mathrm{g} / \mathrm{dL} ; 95 \% \mathrm{Cl},-1.67$ to -0.05 ), However, there was significant heterogeneity between studies $\left(I^{2}=53.2 \% ; p=0.012\right)$. Therefore, these results should not be considered reliable in indicating the effectiveness of BCAA on cortisol concentration after supplementation. In a subgroup analysis based on follow-up times, intake of BCAA had no significant effect on lowering cortisol concentration in $<60$ and $60 \leq \mathrm{min}$ follow-up times after exercise, although we observed significantly lower values of cortisol concentration during $120 \leq$ min post exercise follow-up with BCAA (WMD $=-1.92 \mu \mathrm{g} / \mathrm{dL}$; $95 \% \mathrm{Cl},-2.52$ to -1.32$)$, compared to placebo. We excluded follow-up times of more than $180 \mathrm{~min}$ in our analysis. There was no evidence of publication bias among the studies examining the effects of BCAA on cortisol concentration ( $p=0.36$, Begg's test; $p=0.55$, Egger's test).

\section{The effects of BCAA supplementation on lactate concentration}

Among the 15 studies that recorded lactate concentration (279 participants), four studies applied more than 1 day BCAA supplementation $[10,29,31,36]$. We therefore separated the analysis of acute BCAA administration (1 day) and more than 1 day BCAA supplementation (from 6 to 30 days). We conducted subgroup analysis based on follow-up times in acute BCAA supplementation in $<60$ and $60 \leq$ min after exercise and in more than 1 day BCAA supplementation, immediately post exercise ( 0 min) and 30 or 60 min post exercise.

Pooled results showed no significant difference in all follow-up times (overall WMD $=0.06 \mathrm{mmol} / \mathrm{L} ; 95 \% \mathrm{Cl},-0.09$ to 0.21 ) in acute BCAA supplementation, and there was no significant heterogeneity between studies $\left(I^{2}=0.0 \% ; p=0.864\right)$ (Fig. 3 ). Moreover, a sensitivity analysis indicated that the result was not excessively influenced by any one study. There was no evidence of publication bias among studies after examining the effects of acute BCAA supplementation on lactate ( $p=0.59$, Begg's test; $p=0.78$, Egger's test).

In addition, Fig. 4 shows that intake of BCAA for more than 1 day had no significant effect on lowering lactate concentration in the follow-up times post exercise, compared to a placebo (overall WMD $=-0.09 \mathrm{mmol} / \mathrm{L} ; 95 \% \mathrm{Cl},-0.33$ to 0.14 ). There was no evidence of significant heterogeneity between the effect sizes of the included studies $\left(I^{2}=0.0 \% ; p=0.381\right)$. The sensitivity analysis indicated that the result was not excessively influenced by any one study. There was no evidence of publication bias among studies examining the effects of more than 1 day BCAA supplementation on lactate ( $p=0.47$, Begg's test; $p=0.61$, Egger's test).

Further subgroup analysis based on the dose of BCAA supplementation, exercise type, and training status is presented in Table 3. We divided the dose of BCAA into low and high based on a $5 \mathrm{gr} /$ day cut-off point. In addition, exercise was subgrouped based on aerobic vs. anaerobic and trained and vs. untrained status. As illustrated in Table 3, there was no significant difference in subgroup analysis for insulin and cortisol. There was a significant decrease in ammonia by $\geq 5 \mathrm{~g} /$ day BCAA supplementation, aerobic exercise, and untrained status. However, due to high heterogeneity ( $p$ for heterogeneity $=0.00$ ), these results should not be considered reliable. Moreover, there was a significant decrease in lactate in aerobic exercise (WMD $=-0.22 \mathrm{mmol} / \mathrm{L} ; 95 \% \mathrm{Cl},-0.39$ to -0.06 ) and trained status (WMD $=-0.25$ $\mathrm{mmol} / \mathrm{L} ; 95 \% \mathrm{Cl},-0.42$ to -0.08$)$. There was no evidence of significant heterogeneity between the effect sizes of the included studies $\left(\mathrm{I}^{2}=\right.$ $0.0 \% ; p=0.87)$ and $\left(I^{2}=0.0 \% ; p=0.93\right)$, respectively. 
Table 3

Subgroup Analysis to Assess the Effect of BCAA Supplementation on Insulin, Cortisol, Ammonia and Lactate.

\begin{tabular}{|c|c|c|c|c|c|}
\hline Subgrouped by & No. of trials & Effect size $^{1}$ & $95 \% \mathrm{Cl}$ & $\mathrm{I}^{2}(\%)$ & $p$ for heterogeneity \\
\hline \multicolumn{6}{|l|}{ Insulin } \\
\hline \multicolumn{6}{|l|}{ Dosage } \\
\hline$\geq 5 \mathrm{~g} /$ day & 22 & 0.46 & -0.38 to 1.30 & 0.00 & 0.62 \\
\hline$<5 \mathrm{~g} /$ day & 14 & 0.69 & -0.30 to 1.69 & 83.8 & 0.00 \\
\hline \multicolumn{6}{|l|}{ Exercise type } \\
\hline Aerobic & 21 & 0.51 & -0.26 to 1.31 & 72.6 & 0.00 \\
\hline Anaerobic & 15 & 0.66 & -1.19 to 2.51 & 47.7 & 0.02 \\
\hline \multicolumn{6}{|l|}{ Training status } \\
\hline Trained & 17 & 2.11 & -0.03 to 4.26 & 77.5 & 0.00 \\
\hline Untrained & 16 & -0.90 & -1.20 to -0.60 & 0.00 & 0.53 \\
\hline \multicolumn{6}{|l|}{ Cortisol } \\
\hline \multicolumn{6}{|l|}{ Dosage } \\
\hline$\geq 5 \mathrm{~g} /$ day & 8 & -0.57 & -1.36 to 0.21 & 10.3 & 0.35 \\
\hline$<5 \mathrm{~g} /$ day & 7 & -0.27 & -1.54 to 1.00 & 83.2 & 0.00 \\
\hline \multicolumn{6}{|l|}{ Exercise type } \\
\hline Aerobic & 8 & -0.57 & -1.36 to 0.21 & 10.3 & 0.35 \\
\hline Anaerobic & 7 & -0.27 & -1.54 to 1.00 & 83.2 & 0.00 \\
\hline \multicolumn{6}{|l|}{ Training status } \\
\hline Trained & 11 & -0.46 & -1.04 to 0.12 & 0.00 & 0.58 \\
\hline Untrained & 2 & -1.20 & -3.16 to 0.76 & 92.8 & 0.00 \\
\hline \multicolumn{6}{|l|}{ Ammonia } \\
\hline \multicolumn{6}{|l|}{ Dosage } \\
\hline$\geq 5 \mathrm{~g} /$ day & 16 & -8.90 & -14.12 to -3.68 & 0.76 & 0.00 \\
\hline$<5 \mathrm{~g} /$ day & 4 & -4.21 & -10.03 to 1.61 & 0.00 & 0.90 \\
\hline \multicolumn{6}{|l|}{ Exercise type } \\
\hline Aerobic & 10 & -14.84 & -1.42 to -28.25 & 83.9 & 0.00 \\
\hline Anaerobic & 10 & 2.07 & -0.29 to 4.43 & 12.3 & 0.32 \\
\hline \multicolumn{6}{|l|}{ Training status } \\
\hline Trained & 9 & -8.49 & -19.94 to 2.96 & 70.9 & 0.00 \\
\hline Untrained & 11 & -6.14 & -11.22 to -1.06 & 77.2 & 0.00 \\
\hline \multicolumn{6}{|l|}{ Lactate } \\
\hline \multicolumn{6}{|l|}{ Dosage } \\
\hline$\geq 5 \mathrm{~g} /$ day & 16 & 0.09 & -0.04 to 0.22 & 0.00 & 0.74 \\
\hline
\end{tabular}




\begin{tabular}{|llllll|}
\hline Subgrouped by & No. of trials & Effect size $^{1}$ & $95 \%$ Cl & $\mathrm{I}^{2}(\%)$ & p for heterogeneity \\
\hline$<5$ g/day g & 4 & 0.16 & -0.67 to 0.98 & 0.00 & 0.77 \\
\hline Exercise type & & & & & \\
\hline Aerobic & 8 & -0.22 & -0.39 to -0.06 & 0.00 & 0.87 \\
\hline Anaerobic & 12 & -0.12 & -0.33 to 0.09 & 0.00 & 0.99 \\
\hline Training status & & & & & \\
\hline Trained & 6 & -0.25 & -0.42 to -0.08 & 0.00 & 0.93 \\
\hline Untrained & 14 & -0.11 & -0.31 to 0.08 & 0.00 & 0.99 \\
\hline${ }^{1}$ Calculated by random effects model. & & & \\
\hline
\end{tabular}

\section{Discussion}

To our knowledge, the efficacy of BCAA has not been firmly established for hormonal response and fatigue. Therefore, this systematic review and meta-analysis has sought to provide insight into the potential advantages conferred by such supplementation to enable trainers to make informed decisions as to their efficacy and usage. The results of the current meta-analysis, performed in 20 randomized controlled trials, revealed no noticeable effects of BCAA supplementation in decreasing fatigue substances and hormone levels during training protocols of different durations. The major finding of this study was the observation of significantly lower values of cortisol concentration during 2 hours and more post exercise with BCAA. Thus, our findings support those of previous investigators, namely, that amino acid ingestion is capable of attenuating exercise-induced increases in cortisol [26].

Cortisol is a catabolic hormone and the main glucocorticoid hormone in humans, secreted from the adrenal cortex in response to psychological and physical stress [37]. While cortisol increases during exercise, most of the changes and effects of this hormone occur after exercise during early recovery. Short-term elevation in plasma cortisol concentration, within the physiological range, stimulates proteolysis and elevates plasma leucine concentration and utilization. A fraction of plasma BCAA would seem to be utilized for protein synthesis, in contradiction to the cortisol protein synthesis inhibitory mechanism [38]. BCAAs slow the release of essential amino acids from active muscles, prevent exercise-induced muscle proteolysis, reduce muscle damage, and increase muscle protein synthesis during the recovery period $[12,39]$. It can hence be concluded that part of the anticatabolic effect of BCAAs is related to lower values of cortisol concentration.

A review paper by Hormoznejad et al. [40] reported that, in order to assess fatigue, plasma ammonia activity and plasma lactate concentration are widely used as markers. However, the above meta-analysis was performed based on ammonia and lactate. These factors are not only the most used outcomes: they are the best markers of muscle fatigue [28, 33, 35]. Data for ammonia was heterogenic and a meta-analysis was not undertaken. Despite the high heterogeneity of the data, a meta-analysis was conducted previously without any subgroup for follow-up time [40], and in our opinion, these results should not be considered reliable. Moreover, intake of BCAA for any duration had no significant effect on lowering lactate concentration in the follow-up times post exercise, compared to a placebo. Nevertheless, without considering follow-up times, with an overall analysis BCAA was effective in lactate reduction for subgroups of aerobic exercise and trained status of athletes (Table 3 ).

The rate of lactate production exceeds the rate of removal during high-intensive exercise. The excess lactate facilitates acidosis and suppresses the enzymatic activation related to glycolysis, which impedes ATP synthesis and finally leads to fatigue. McLean et al. [34] suggested that a $77 \mathrm{mg} / \mathrm{kg}$ dose of BCAA does not significantly alter the overall distribution of pyruvate into lactate and alanine, compared with placebo. Matsumoto et al. [25] reported an increase in circulatory BCAA levels and suggested that BCAA supplementation induced an increase in BCAA oxidation during the exercise test. It was thus speculated that an increase in acetyl-CoA and succinyl-CoA supply to the TCA cycle via the BCAA catabolic pathway suppressed lactate production during the exercise test. In a study by Kim et al. [33], lactate concentrations of the two groups of BCAA and controls, respectively, showed a statistically significant increase at 30 min into exercise. Lactate concentrations in the BCAA intake group indicated a statistically meaningful decrease immediately after exercise and returned to a stable level at $30 \mathrm{~min}$ after exercise. However, in the present meta-analysis, we could not analyze immediately postexercise follow-up due to the high heterogeneity of the data.

Page $10 / 16$ 
Several factors can affect the high heterogeneity and the inconclusive findings that have been reported. Some of these are: the percentage of leucine, isoleucine, and valine; different manufacturers of BCAA; and variations in BCAA classifications between countries. All these factors may contribute to the inconsistencies in results. Moreover, the studies included in this review reported different dosages, ranging from $1.5 \mathrm{~g} /$ day [27] to $64 \mathrm{~g} /$ day [31].

\section{Conclusion}

To our knowledge, this is the first systematic review and meta-analysis to evaluate the effects of BCAA on hormonal response and fatigue after exercise. The current evidence-based information demonstrates that supplementation with BCAA is better than passive recovery or rest after various forms of damaging and exhausting exercise. The advantages relate to a reduction in cortisol concentration after $2 \mathrm{~h}$ and ameliorated muscle function because of a probable attenuation of fatigue substances immediately after exercise. Furthermore, in aerobic exercise and trained status of participants, the effect of BCAA was significant in achieving lactate reduction. It seems that BCAA is more effective for trained athletes who do aerobic exercise. Further research is necessary to quantify BCAA efficacy in a homogenous supplementation strategy and the same exercise protocol over a longer timeframe and to clarify possible interactions

with diet and environment. In addition, the effects of BCAA on other hormones, for example testosterone and metabolic parameters, and the cost-effectiveness of this supplement should be clarified in further studies.

\section{Declarations}

\section{Consent for publication:}

Not applicable

\section{Competing interests:}

There was no competing financial interest in relation to the current study.

\section{Acknowledgements:}

The results of the current study do not constitute endorsement of the product by the authors or the journal.

\section{References}

1. Rahimi, R., et al., Creatine supplementation alters the hormonal response to resistance exercise. Kinesiology, 2010. 42(1): p. 28-35.

2. Dalbo, V.J., et al., Effects of age on serum hormone concentrations and intramuscular proteolytic signaling before and after a single bout of resistance training. The Journal of Strength \& Conditioning Research, 2011. 25(1): p. 1-9.

3. Kimball, S.R., P.A. Farrell, and L.S. Jefferson, Invited Review: Role of insulin in translational control of protein synthesis in skeletal muscle by amino acids or exercise. Journal of applied physiology, 2002. 93(3): p. 1168-1180.

4. Hazar, S., et al., The effect of graded maximal aerobic exercise on some metabolic hormones, muscle damage and some metabolic end products in sportsmen. Scientific Research and Essays, 2011. 6(6): p. 1337-1343.

5. Casto, K.V. and D.A. Edwards, Before, during, and after: how phases of competition differentially affect testosterone, cortisol, and estradiol levels in women athletes. Adaptive Human Behavior and Physiology, 2016. 2(1): p. 11-25.

6. Morton, R.W., et al., Neither load nor systemic hormones determine resistance training-mediated hypertrophy or strength gains in resistance-trained young men. Journal of Applied Physiology, 2016. 121(1): p. 129-138.

7. Chandler, R., et al., Dietary supplements affect the anabolic hormones after weight-training exercise. Journal of applied physiology, 1994. 76(2): p. 839-845.

8. Fahey, T.D., et al., The effects of intermittent liquid meal feeding on selected hormones and substrates during intense weight training. International journal of sport nutrition, 1993. 3(1): p. 67-75.

9. Shimomura, Y., et al., Branched-chain amino acid supplementation before squat exercise and delayed-onset muscle soreness. International journal of sport nutrition and exercise metabolism, 2010. 20(3): p. 236-244. 
10. Koo, G.H., et al., Effects of supplementation with BCAA and L-glutamine on blood fatigue factors and cytokines in juvenile athletes submitted to maximal intensity rowing performance. Journal of physical therapy science, 2014. 26(8): p. 1241-1246.

11. Strüder, $\mathrm{H}$., et al., Influence of paroxetine, branched-chain amino acids and tyrosine on neuroendocrine system responses and fatigue in humans. Hormone and Metabolic Research, 1998. 30(04): p. 188-194.

12. Rahimi, M.H., et al., Branched-chain amino acid supplementation and exercise-induced muscle damage in exercise recovery: A metaanalysis of randomized clinical trials. Nutrition, 2017. 42: p. 30-36.

13. Fouré, A. and D. Bendahan, Is branched-chain amino acids supplementation an efficient nutritional strategy to alleviate skeletal muscle damage? A systematic review. Nutrients, 2017. 9(10): p. 1047.

14. Kawanago, M., et al., Dietary branched-chain amino acid supplementation affects growth and hepatic insulin-like growth factor gene expression in yellowtail, Seriola quinqueradiata. Aquaculture Nutrition, 2015. 21(1): p. 63-72.

15. Scherer, T., et al., Chronic intranasal insulin does not affect hepatic lipids but lowers circulating BCAAs in healthy male subjects. The Journal of Clinical Endocrinology \& Metabolism, 2017. 102(4): p. 1325-1332.

16. Ball, D., Metabolic and endocrine response to exercise: sympathoadrenal integration with skeletal muscle. Journal of Endocrinology, 2015. 224(2): p. R79-R95.

17. Sheikholeslami-Vatani, D. and S. Ahmadi, Effect of oral branched-chain amino acid supplementation prior to resistance exercise on metabolic hormones, plasma amino acids, and serum indices of muscle damage in the recovery period. Topics in Clinical Nutrition, 2016. 31(4): p. 346-354.

18. Glynn, E.L., et al., Impact of combined resistance and aerobic exercise training on branched-chain amino acid turnover, glycine metabolism and insulin sensitivity in overweight humans. Diabetologia, 2015. 58(10): p. 2324-2335.

19. Liberati, A., et al., The PRISMA statement for reporting systematic reviews and meta-analyses of studies that evaluate health care interventions: explanation and elaboration. PLoS medicine, 2009. 6(7): p. e1000100.

20. Davis, J., et al., Effects of branched-chain amino acids and carbohydrate on fatigue during intermittent, high-intensity running. International journal of sports medicine, 1999. 20(05): p. 309-314.

21. Mikulski, T., et al., Effects of supplementation with branched chain amino acids and ornithine aspartate on plasma ammonia and central fatigue during exercise in healthy men. Folia neuropathologica, 2015. 53(4): p. 377-386.

22. Higgins, J.P., et al., The Cochrane Collaboration's tool for assessing risk of bias in randomised trials. Bmj, 2011. 343: p. d5928.

23. Tobias, A., Assessing the influence of a single study in the meta-anyalysis estimate. Stata Technical Bulletin, 1999. 8(47).

24. Apró, W. and E. Blomstrand, Influence of supplementation with branched-chain amino acids in combination with resistance exercise on p70S6 kinase phosphorylation in resting and exercising human skeletal muscle. Acta physiologica, 2010. 200(3): p. 237-248.

25. Matsumoto, K., et al., Branched-chain amino acids and arginine supplementation attenuates skeletal muscle proteolysis induced by moderate exercise in young individuals. International journal of sports medicine, 2007. 28(06): p. 531-538.

26. Sharp, C.P. and D.R. Pearson, Amino acid supplements and recovery from high-intensity resistance training. The Journal of Strength \& Conditioning Research, 2010. 24(4): p. 1125-1130.

27. Ghaderi, M. and K. Azizbeigi, Hormonal responses to acute resistance exercise after branched-chain amino acids supplementation. International Medical Journal, 2014. 22(1): p. 1-5.

28. Hsu, M.-C., et al., Effects of BCAA, arginine and carbohydrate combined drink on post-exercise biochemical response and psychological condition. Chin J Physiol, 2011. 54(2): p. 71-78.

29. Bigard, A.X., et al., Branched-chain amino acid supplementation during repeated prolonged skiing exercises at altitude. International Journal of Sport Nutrition and Exercise Metabolism, 1996. 6(3): p. 295-306.

30. Carli, G., et al., Changes in the exercise-induced hormone response to branched chain amino acid administration. European journal of applied physiology and occupational physiology, 1992. 64(3): p. 272-277.

31. Mourier, A., et al., Combined effects of caloric restriction and branched-chain amino acid supplementation on body composition and exercise performance in elite wrestlers. International journal of sports medicine, 1997. 18(01): p. 47-55.

32. Van Hall, G., et al., Ingestion of branched-chain amino acids and tryptophan during sustained exercise in man: failure to affect performance. The Journal of Physiology, 1995. 486(3): p. 789-794.

33. Kim, D.-H., et al., Effect of BCAA intake during endurance exercises on fatigue substances, muscle damage substances, and energy metabolism substances. Journal of exercise nutrition \& biochemistry, 2013. 17(4): p. 169. 
34. MacLean, D., T. Graham, and B. Saltin, Branched-chain amino acids augment ammonia metabolism while attenuating protein breakdown during exercise. American Journal of Physiology-Endocrinology And Metabolism, 1994. 267(6): p. E1010-E1022.

35. Watson, P., S.M. Shirreffs, and R.J. Maughan, The effect of acute branched-chain amino acid supplementation on prolonged exercise capacity in a warm environment. European journal of applied physiology, 2004. 93(3): p. 306-314.

36. De Palo, E., et al., Plasma lactate, GH and GH-binding protein levels in exercise following BCAA supplementation in athletes. Amino acids, 2001. 20(1): p. 1-11.

37. Brownlee, K.K., A.W. Moore, and A.C. Hackney, Relationship between circulating cortisol and testosterone: influence of physical exercise. Journal of sports science \& medicine, 2005. 4(1): p. 76.

38. Simmons, P.S., et al., Increased proteolysis. An effect of increases in plasma cortisol within the physiologic range. The Journal of clinical investigation, 1984. 73(2): p. 412-420.

39. Zhang, Y., et al., Effects of branched-chain amino acid supplementation on plasma concentrations of free amino acids, insulin, and energy substrates in young men. Journal of nutritional science and vitaminology, 2011. 57(1): p. 114-117.

40. Hormoznejad, R., A.Z. Javid, and A. Mansoori, Effect of BCAA supplementation on central fatigue, energy metabolism substrate and muscle damage to the exercise: a systematic review with meta-analysis. Sport Sciences for Health, 2019: p. 1-15.

\section{Figures}

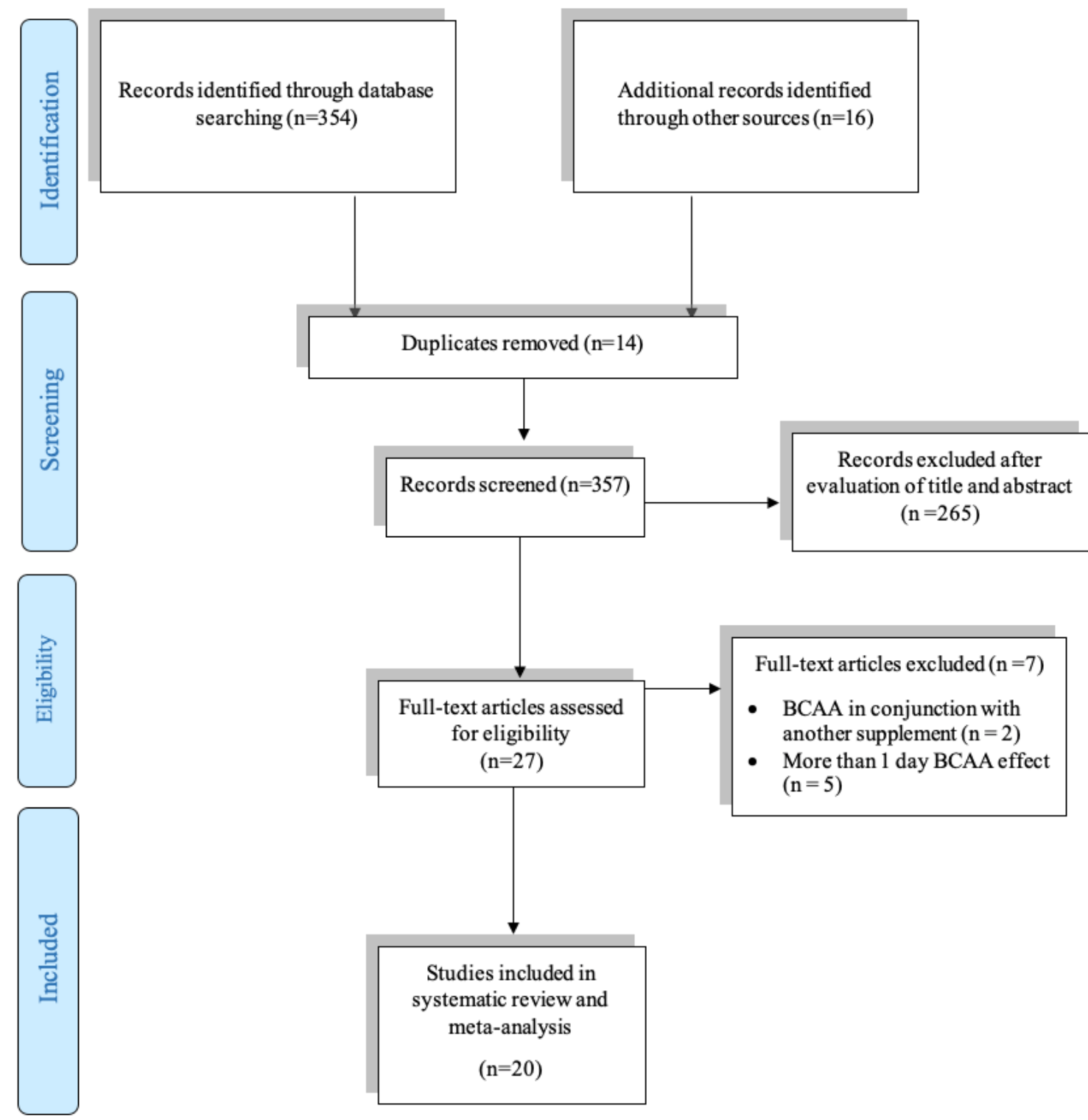

Figure 1 
Preferred Reporting Items for Systematic Reviews and Meta-Analyses (PRISMA) flow diagram of study selection process.

Author (Year)

$<60$ minutes

Atashak (2014)

Lysenko (2016)

Lysenko (2016)

Sheikholeslami (2016)

Strüder (1998)

Strüder (1998)

Subtotal (l-squared $=0.0 \%, p=0.929$ )

$\geq 60$ minutes

Atashak (2014)

Carli (1992)

Lysenko (2016)

Strüder (1998)

Subtotal $(1$-squared $=0.0 \%, p=0.606)$

$\geq 120$ minutes

Atashak (2014)

Carli (1992)

Sheikholeslami (2016)

Subtotal (l-squared $=0.0 \%, p=0.459$ )

Overall $($ l-squared $=53.2 \%, p=0.012)$
-13.4
WMD (95\%CL) \% Weight

$0.10(-1.97,2.17) \quad 9.29$

$4.10(-5.19,13.39) \quad 0.73$

$-1.30(-8.28,5.68) \quad 1.26$

$-0.20(-0.95,0.55) \quad 19.93$

$-0.70(-5.20,3.80) \quad 2.83$

$-1.74(-7.12,3.64) \quad 2.05$

$-0.19(-0.87,0.49) \quad 36.09$

$-1.70(-7.15,3.75) \quad 2.00$

$0.20(-0.62,1.02) \quad 19.27$

$-1.90(-8.12,4.32) \quad 1.57$

$-2.57(-7.87,2.73) \quad 2.11$

$0.06(-0.73,0.86) \quad 24.95$

$-1.60(-7.65,4.45) \quad 1.65$

$-1.40(-2.42,-0.38) \quad 17.38$

$-2.20(-2.95,-1.45) \quad 19.93$

$-1.92(-2.52,-1.32) \quad 38.97$

$-0.86(-1.67,-0.05) \quad 100.00$

Figure 2

Forest plot of the effect of BCAA supplementation on cortisol concentration subgrouped by study follow ups, WMD = weighted mean difference; $\mathrm{Cl}$ = confidence interval. 
Author (year)

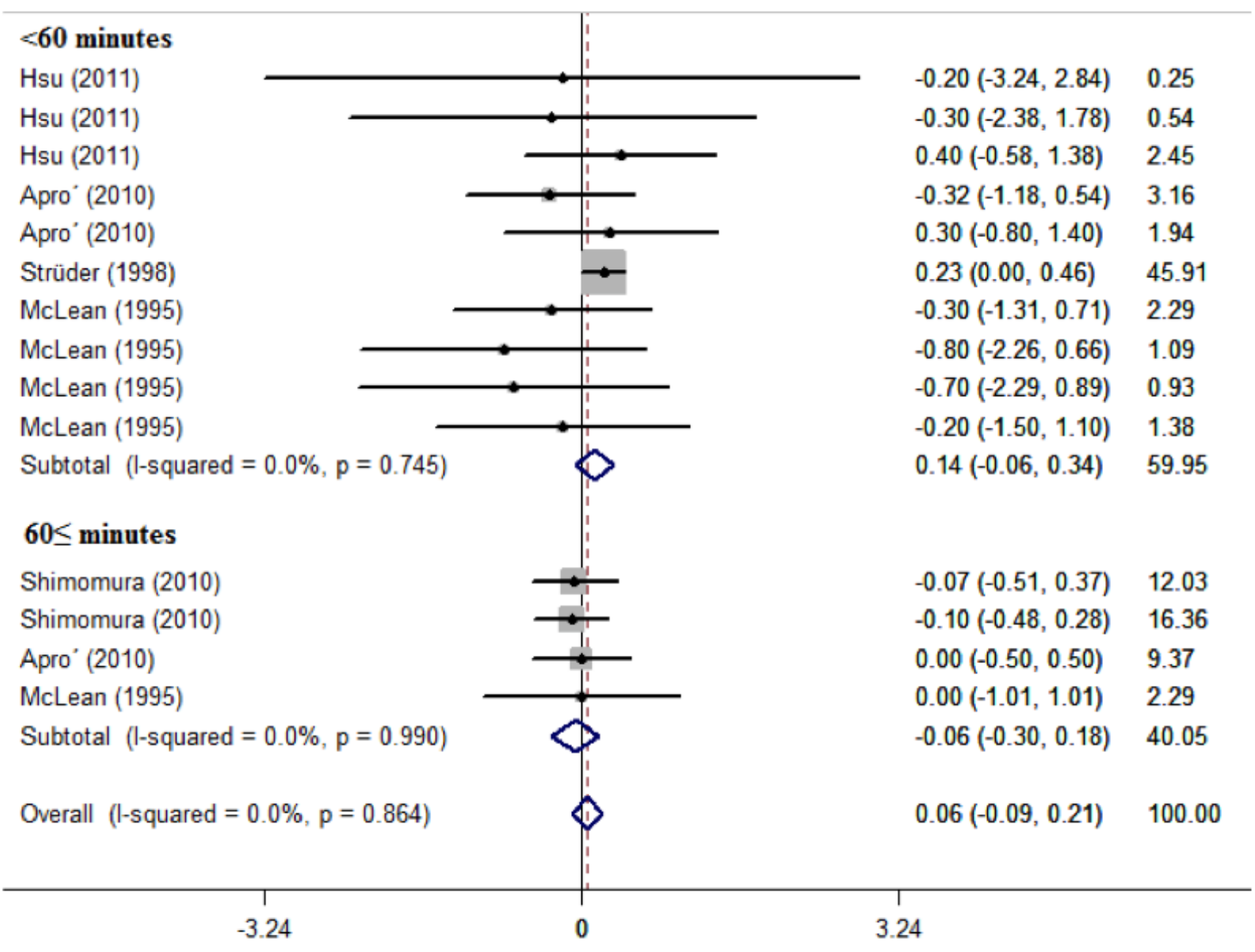

Figure 3

Forest plot of the effect of acute BCAA supplementation on lactate level subgrouped by study follow ups, WMD = weighted mean difference; $\mathrm{Cl}=$ confidence interval. 


\begin{tabular}{|c|c|c|}
\hline Author (year) & WMD $(95 \%$ CL) & $\%$ Weight \\
\hline Immediately post exercise & \multirow[b]{2}{*}{$0.96(-2.80,4.72)$} & \multirow[b]{2}{*}{0.38} \\
\hline Koo (2014) & & \\
\hline Matsumoto (2006) & $-0.15(-4.26,3.96)$ & 0.32 \\
\hline De Palo (1999) & $-1.92(-3.84,0.00)$ & 1.45 \\
\hline Mourier (1997) & $1.41(-1.57,4.39)$ & 0.61 \\
\hline Bigard (1996) & $-0.12(-0.24,0.00)$ & 82.51 \\
\hline Subtotal $(1-$ squared $=14.8 \%, p=0.320)$ & $-0.22(-0.94,0.51)$ & 85.27 \\
\hline \multicolumn{3}{|l|}{30 or 60 minutes' post exercise } \\
\hline Koo (2014) & $1.34(-0.51,3.19)$ & 1.56 \\
\hline De Palo (1999) & $-0.23(-1.69,1.23)$ & 2.49 \\
\hline De Palo (1999) & $0.05(-0.63,0.73)$ & 10.67 \\
\hline Subtotal (l-squared $=0.0 \%, p=0.381)$ & $0.13(-0.45,0.72)$ & 14.73 \\
\hline Overall $(1-$ squared $=4.6 \%, p=0.394)$ & $-0.09(-0.33,0.14)$ & 100.00 \\
\hline 1 & 1 & \\
\hline
\end{tabular}

Figure 4

Forest plot of the effect of more than 1 day BCAA supplementation on lactate level subgrouped by study follow ups, WMD $=$ weighted mean difference; $\mathrm{Cl}=$ confidence interval. 